\title{
Exploring the impact of a large gender- sensitised health promotion program: the Sons of the West program
}

\author{
Carolyn L Deans $s^{a, b}$ \\ a Institute for Health and Sport, Victoria University, Melbourne, Australia \\ b Corresponding author: carolyn.deans@vu.edu.au
}

\section{Article history}

Publication date: March 2021

Citation: Deans CL. Exploring the impact of a large gender-sensitised health promotion program: the Sons of the West program. Public Health Res Pract. 2021;31(1):e30012001. First published: 29 January 2020. https://doi.org/10.17061/ phrp30012001

\section{Key points}

- Sons of the West is a gender-sensitised health promotion program for men associated with a large Australian Football League club in Victoria, Australia, with more than 1000 participants in 2017

- An evaluation found that the 10 -week program achieved improvements in men's psychological wellbeing, connectedness and resilience from pre-program to postprogram

- The program also appeared to overcome barriers to psychological help-seeking, with high rates of participants seeking mental healthcare

\section{Abstract}

Aim: Evaluation of the outcomes of gender-sensitised programs that target men with poor health behaviours is lacking. The purpose of this study was to provide an understanding of the psychosocial changes related to participation in the Sons of the West (SOTW) men's health promotion program run by the Western Bulldogs Community Foundation.

Methods: All men who participated in SOTW during 2017 were asked to complete surveys at the beginning and end of the program. The surveys were quantitative measures of psychological wellbeing (Kessler Psychological Distress Scale, K10), social connectedness and loneliness (UCLA Loneliness Scale, UCLA-L), and resilience (Brief Resilience Scale, BRS). In addition, we analysed participants' responses to an offer within the program to provide psychological support to any participant in need. Men were provided with a participant code so that data could be matched at the beginning and end of the program.

Results: A high participation rate (776/1003) was achieved. There were statistically significant improvements in mean K10 scores from pre(population mean $[\mathrm{M}]=17.34$; standard deviation $[\mathrm{SD}]=6.98$ ) to postprogram $(M=14.98 ; S D=6.27)$, and for matched samples $(p<0.001)$. Matched samples also showed significant improvements in mean UCLA-L scores from pre- $(\mathrm{M}=38.58 ; \mathrm{SD}=10.87)$ to post-program $(\mathrm{M}=37.42$; $\mathrm{SD}=10.87)$, and mean BRS scores from pre- $(\mathrm{M}=3.44$; $\mathrm{SD}=0.79)$ to postprogram $(M=3.62 ; S D=0.74)$. Results from the psychological help-seeking question showed that one-third of participants were open to the concept of receiving additional psychological support.

Conclusions: This preliminary data shows that a broad-ranging, gendersensitised health promotion program can have a significant effect on psychosocial health of male participants. The findings provide insights for future research, and suggest the program has potential for generalisation to other populations. 


\section{Introduction}

Australian males experience shorter life expectancy and higher mortality rates than women, for example, men die from heart disease at a standardised death rate nearly twice that of women. ${ }^{1}$ Men are also a higher risk of many cancers and non-gender-specific chronic diseases than women. ${ }^{2}$ The difference in health status between genders is often exacerbated by a lack of awareness of health risk factors, poor lifestyle choices, poor health-related behaviours and lower rates of health service utilisation among men..$^{2,3}$ Australian men not only access health services at lower rates than women, but do so later in the course of their illness and are more likely to discontinue treatment prematurely. ${ }^{4}$ The difference is not related to the availability of healthcare, but appears to be associated with utilisation of that care. ${ }^{5}$ These factors are reflected in the health status of the diverse population of men living in western Victoria. ${ }^{6}$

This difference in health behaviours between genders is particularly marked in relation to help-seeking for psychological difficulties. Compared with women, men are more likely to perceive and report mental health stigma, and are less likely to engage in mental healthpromoting activities. ${ }^{7,8}$ Among men in low-income groups, these barriers to healthcare utilisation have been found to relate to perceptions of healthcare providers, such as distrust of professionals, or distrust of the usefulness of the service. ${ }^{9}$

Research on the social determinants of male health and the way in which these influence health outcomes, behaviours and health service use has been limited, although some studies have now been established. ${ }^{10} \mathrm{~A}$ number of psychological concepts have been posited as factors that may be involved in healthcare barriers for men. There are several known barriers to care, with the most researched being adherence to social norms surrounding masculinity, social networks, stigma and the perceived need for care. ${ }^{11-14}$

However, there is less research focusing on how poor lifestyle choices, such as diet, or health-related behaviours, such as social contact, can be changed in a positive direction. The importance of behaviour change in healthcare is substantial, in terms of both morbidity and mortality risks. ${ }^{15}$ Many existing interventions that target health-related behaviours rely on influencing the way people consciously think about their behaviour, assuming that people change behaviour when their motivations and intentions are changed. However, a substantial proportion of variance in behaviour is not explained by intentions. Several meta-analyses suggest that changing intentions accounts for less than one-third of the variance in behaviour change. ${ }^{16}$

There is therefore a need to develop and evaluate health promotion programs that pay attention to barriers to care, but also identify opportunities for positive change. For example, social support is a powerful influence on human behaviour, and programs that harness it can help to compensate for other barriers to change. ${ }^{17}$ Increasing flexibility in men's understanding of masculinity has for some time been identified as an agent for facilitating health-related behaviours. Indeed, gender-sensitised programs appear to have success for both male and female audiences. ${ }^{18}$ However, Smith ${ }^{19}$ suggests that many men's health promotion activities in Australia are aligned to hegemonic constructions of masculinity, and therefore perpetuate instead of weaken problematic behaviours in relation to healthcare and help-seeking. Thus, there is not presently consensus as to what factors a gendersensitised health program should target.

\section{The Sons of the West health promotion program}

The Western Bulldogs Community Foundation (WBCF) is a not-for-profit foundation established by an Australian Football League club, with the aim of assisting the community of western Melbourne. This region has some of the lowest socio-economic area rankings in Melbourne and Victoria, and more than $45 \%$ of the population speaks a language other than English at home.20,21 The Western Bulldogs Football Club established the Sons of the West (SOTW) health promotion program in 2014. ${ }^{22}$ The program targets men aged 18 and older who live in Melbourne's west and regional western Victoria. The program is free and men are encouraged to join and partipate in activities, for up to three years.

In partnership with local councils and health organisations such as the Heart Foundation, SOTW promotes men's health and behaviour change using the reach of the Western Bulldogs Football Club as an engagement tool. In 2017, the 'premiership season' of the SOTW program was delivered over a 10-week period from May to July. Each week a SOTW partner organisation provided group education sessions at each location on a relevant health topic, such as healthy eating and cooking skills, or psychological training based on cognitive behavioural training principles, as well as 1 hour of supportive group-based physical activity. This was preceded by a separate 10-week 'pre-season' focused on physical activity only. The pre-season part of the program was not analysed in this study. In 2017, the SOTW program was delivered in 17 locations across nine local government areas. Since 2014, the program has rapidly increased in size, and in 2017 had a participant base of more than 1600 men.

Anticipated immediate outcomes of the program, including willingness to act, empowerment, recall of information, attitudes towards physical activity and impact on behaviours outside the program, have been shown to be achievable. ${ }^{23}$ These outcomes are common to a range of programs that target inactive men in Australia and internationally. ${ }^{24}$ There is less evidence about whether health promotion programs are able to achieve outcomes in the areas of psychological health and social connectedness. The SOTW program targets 
psychological resilience among other broad health goals such as health literacy and chronic disease management.

\section{Aims}

The aims of this evaluation were to assess the SOTW program's capacity to achieve psychosocial outcomes in participants across the 10-week premiership program. This is part of a broader aim to collect data for further analysis of innovative ways to deliver men's health promotion programs.

Specifically, we were interested in changes in the participants':

1) Psychological wellbeing and resilience

2) Social connectedness/loneliness

3) Mental health help-seeking behaviour (as a form of mental health literacy).

\section{Methods}

\section{Design}

The study involved analysis of pre- (week 1) and postprogram (week 10) data from SOTW 2017 participants. Data was collected at all 17 SOTW sites.

\section{Recruitment and consent}

During Week 1 of the program, all SOTW attendees ( $n=1003$ ) were invited to participate in the research study with surveys to be used for data analysis. Participants provided signed consent and completed surveys before the first session. A small number of men who did not attend in Week 1, or who took a week to decide whether to be involved, completed surveys in Week 2. Retrospective data usage for the purpose of further analysis and publication was approved by the Victoria University Human Research Ethics Committee (HRE18-023).

\section{Measures}

All measures were administered at pre-program (week 1) and post-program (week 10) stages.

The Kessler Psychological Distress Scale (K10) is a measure of psychological distress used by the Australian Bureau of Statistics (ABS) for national and state health surveys. The K10 has sound psychometric properties. ${ }^{25}$ Scores range from 10 to 50, with low scores indicating low levels of psychological distress. ABS guidelines on categories of $\mathrm{K} 10$ scores were used. ${ }^{26}$

The Brief Resilience Scale (BRS) assesses the ability to recover from stressful circumstances ${ }^{27}$ It shows validity and predictive ability for a range of psychological concepts. ${ }^{27}$ The author reports normative scores between 3.53 and 3.61 in general adult populations, and suggests categorisation of scores into low, normal and high resilience.
The UCLA Loneliness Scale (Version 3; UCLA-L) is designed to measure subjective feelings of loneliness and social isolation. The scale has good reliability and is widely used. ${ }^{28}$ Scores range from 20 to 80 , with low scores indicating low levels of loneliness. The authors provide some indicative guidelines for what constitutes average, frequent and severe loneliness. ${ }^{29}$

\section{Data analysis}

Data were matched using participant codes so no identifying information was used in the analysis. Data for all surveys were analysed using SPSS Statistics for Windows (Armonk, NY: IBM Corp; version 24.0). Initial data screening included review of missing cases and examination of total score plots and missing variables. Little's test for missing completely at random items for all variables was $p<0.001$, suggesting all missing items were missing at random. Cases missing three or more items on the $\mathrm{K} 10$ (>20\% of the scale) were excluded from analysis. Cases with up to two missing items were replaced with expectation-maximisation estimation. Due to the short scale length, cases with any items missing on UCLA-L or BRS were excluded from analysis. Following missing case deletion, $436 \mathrm{~K} 10$ cases, 420 UCLA-L cases and 430 BRS cases were able to be matched pre- to post-program. To determine the significance of change in results across time, dependent samples t-tests were conducted.

\section{Results}

\section{Response rates and demographics}

Data was collected at all 17 SOTW sites with equivalent response rates across sites. A total of 776 participants agreed to participate and completed the surveys during weeks 1-2, with 600 completing a second survey during Week 10. The mean age of respondents was 54 years (standard deviation [SD] = 15.4 years), higher than the ABS-reported median age of Victorian males (35.9 years), and higher than in any of the council areas where SOTW sessions were held. ${ }^{30}$ Two-thirds (66\%) of participants reported that they had one or more chronic health conditions (as defined by the Australian Institute of Health and Welfare, including arthritis; asthma; back problems; cancer; chronic obstructive pulmonary disorders; diabetes; heart disease, stroke or vascular disease; kidney disease; mental conditions; and osteoporosis). This rate was higher than the ABS-reported proportion of Victorians with one or more conditions (48\%). ${ }^{31}$

\section{Impact on psychological wellbeing and resilience}

The mean pre-program $\mathrm{K} 10$ score for all those who completed surveys was $17.34(\mathrm{SD}=6.98)$ and the mean post-program score was $14.98(\mathrm{SD}=6.27)$. 
This is a reduction in the mean score of participants from the moderate distress range to the low distress range. Data is shown in Figure 1 in comparison to the percentages among Victorian males in the ABS 2014-15 National Health Survey. ${ }^{31}$ Rates of distress among SOTW participants decreased over the program to a rate that was similar to the general Victorian male population.

For those who stayed in the program until week 10, there was a statistically significant difference between the mean $\mathrm{K} 10$ score at the commencement of the program $(\mathrm{M}=16.97 ; \mathrm{SD}=6.67)$ and the mean $\mathrm{K} 10$ score derived from the post-program evaluation $(\mathrm{M}=15.13$; $\mathrm{SD}=6.26)$ $\left(\mathrm{t}_{(435)}=7.44 ; p<0.001\right)$.

Mean scores on the BRS at the pre-program stage were below the normative range $(M=3.44 ; S D=0.76)$ and at the post-program stage $(\mathrm{M}=3.57$; $\mathrm{SD}=0.72)$ fell within the normative resilience range. When paired data was used, there was a statistically significant difference for those who stayed in the program between pre-program $(\mathrm{M}=3.44$; $\mathrm{SD}=0.79)$ and post-program $(\mathrm{M}=3.62 ; \mathrm{SD}=0.74)$ scores $\left(\mathrm{t}_{(429)}=-6.46 ; p=<0.001\right)$. It appears that participants improved their BRS scores from just below the normative range to within the normative range during the course of the program. As shown in Figure 2, there was an increase from pre- to post-program in the number of participants in the 'high resilience' category and a decrease in the number of men in the 'low resilience' category. This is strong endorsement of self-reported changes in resilience across the program.

\section{Impact on social connectedness and Ioneliness}

Mean UCLA-L scores at both pre-program $(\mathrm{M}=38.58$; $\mathrm{SD}=10.87)$ and post-program $(\mathrm{M}=37.42 ; \mathrm{SD}=10.87)$ stages were within the average loneliness category.

Figure 1. Distribution of K10 psychological distress scores for the Sons of the West 2017 cohort $(n=436)$, compared with Victorian males

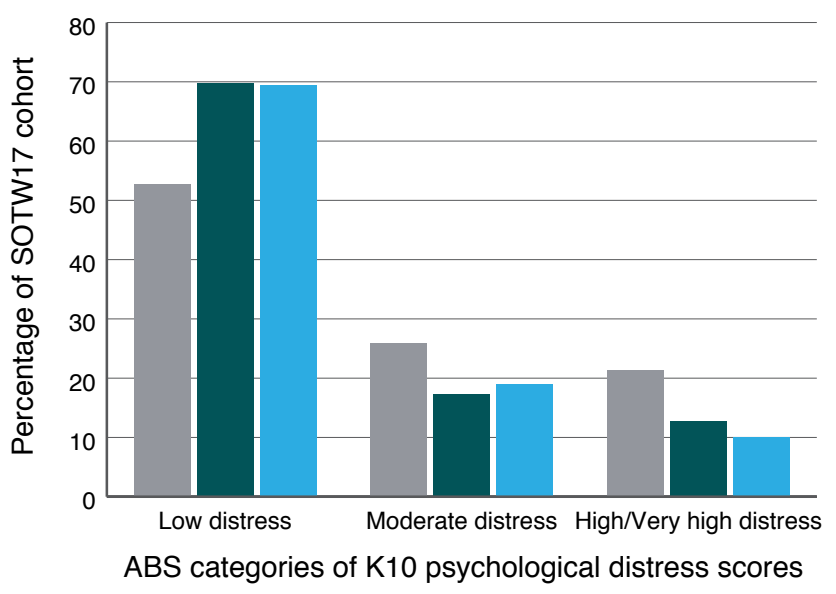

Pre-program Post-program Victorian males

ABS = Australian Bureau of Statistics; SOTW17 = Sons of the West 2017
Figure 2. Distribution of Brief Resilience Scale scores for the Sons of the West 2017 cohort $(n=430)$

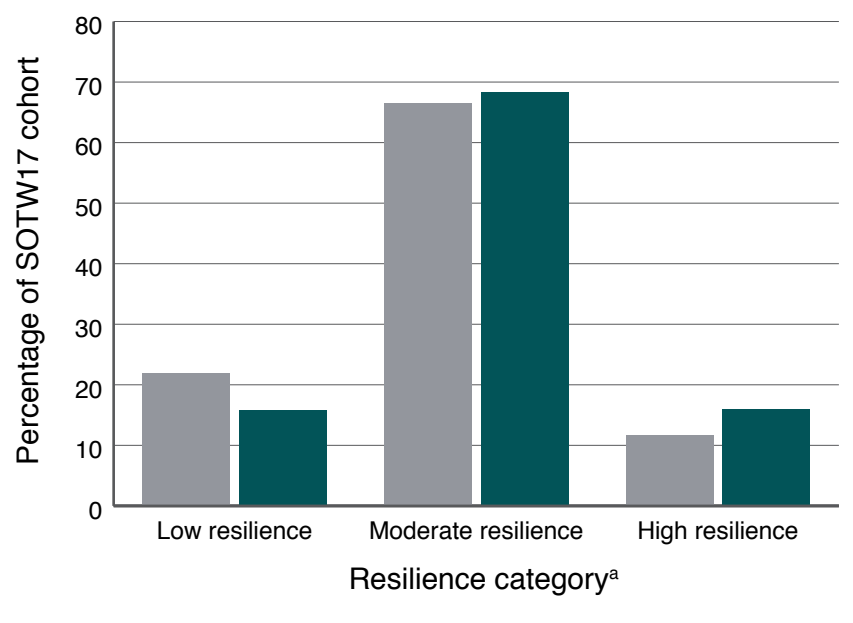

Pre-program Post-program

SOTW17 $=$ Sons of the West 2017

a As defined by Smith et al. International Journal of Behavioral Medicine 2008;15(3):194-200.

Figure 3 shows that the number of participants in the average loneliness category increased and the number in the frequent and severe loneliness categories decreased, but only by a small amount. It should be noted that survey administrators observed that a number of participants had difficulty understanding the wording of the UCLA-L measures. This is reflected in a greater number of missing responses on UCLA-L than on other measures, as well as a large standard deviation within the sample.

Among those who stayed in the program, paired samples showed a statistically significant difference between the mean UCLA-L scores at the commencement of the program $(\mathrm{M}=38.03 ; \mathrm{SD}=10.54)$ and at postprogram evaluation $(\mathrm{M}=37.01$; $\mathrm{SD}=10.81)\left(\mathrm{t}_{(419)}=2.92\right.$; $p=<0.005)$.

\section{Impact on psychological help-seeking}

In addition to psychological support provided within the SOTW program, all SOTW participants were provided with information on mental health support available within the general community. All SOTW participants were also offered (in writing) the option to be contacted by a SOTW provisional psychologist (a psychologist undergoing postgraduate training and practising under supervision) for further engagement. One-third of participants ( $n=253$ ) indicated they would like to take up this offer, and telephone contact was attempted with these participants. Some men did not answer calls, or indicated that they had mistakenly ticked the box, changed their mind or no longer needed assistance. A total of 128 men stated that they required further mental health assistance. 
Figure 3. Distribution of UCLA Loneliness Scale scores for the Sons of the West 2017 cohort $(n=420)$

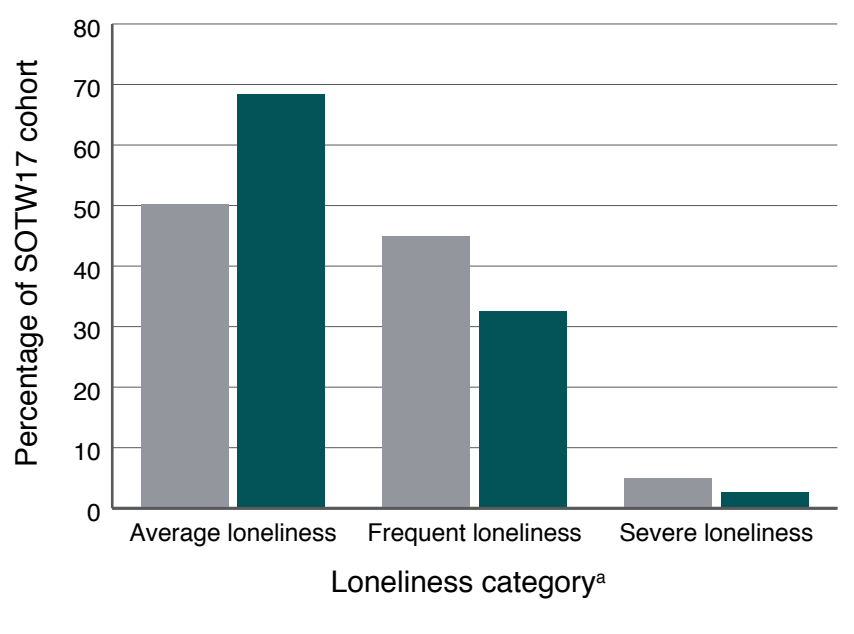

Pre-program Post-program

SOTW17 $=$ Sons of the West 2017

a As defined by UCLA Loneliness Scale authors in Knight et al. Journal of Clinical Psychology 1988;44(2):203-6.

Figure 4 shows that the largest proportion of men (36\%) reported that attending SOTW (without specific additional psychological support) had assisted them with their mental health difficulties. The proportion of men receiving psychological support within the program was similar to the proportion who independently sought or were referred to outside mental health professionals.

\section{Discussion}

SOTW continues to promote men's health and health behaviour change in Victoria's west. From the data provided in this study, the SOTW program appears to meet the intermediate goals identified in program's aims. All areas of psychological wellbeing, individual resilience and social connectedness improved when measured using high-quality instruments, and across a large participant group. The high rates of survey participation may reflect the goodwill among the participant group towards the program. Uptake of the internal psychological support services also suggests that men are far more open to seeking mental health support than has previously been suggested. ${ }^{9}$

\section{Psychological wellbeing}

Research linking men's health promotion programs to psychological outcomes is limited. A study of the Men's Shed program in Australia found it was capable of decreasing social isolation, but there is no research evidence regarding whether it promotes psychological health. ${ }^{32}$ Therefore, the ability of the SOTW program to markedly increase psychological wellbeing scores, and improve resilience even across a brief measure of three items, is remarkable. It appears that a combination of social support, inclusion, participation in meaningful goal setting and the psychological support provided within the program has an impact on a broad scale.

A SOTW 2015 program evaluation $(n=436$ men) showed a $10 \%$ increase in the proportion of men reporting low distress and an $8 \%$ reduction in the proportion of men reporting high distress.22 The 2017 evaluation on which this study is based included a number of men in their second or third year of the program who had also completed evaluation in 2015 , as well as a number of newer first- and second-year attendees. Using the matched 2017 data, there was a $22.6 \%$ increase in the number of men in the K10 low psychological distress category from Week 1 to Week 10. There was a 23.4\% reduction in the number of men who were in the high or very high distress category.

\section{Figure 4. Types of psychological help requested by the Sons of the West 2017 cohort $(n=128)$}

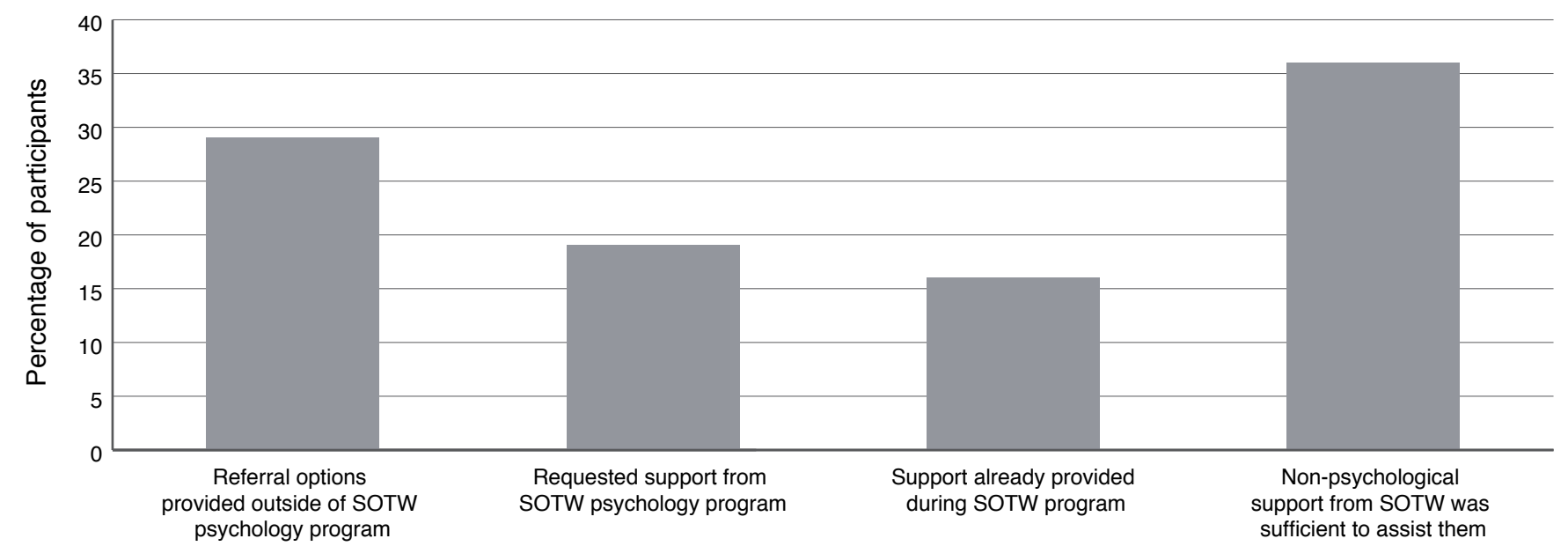




\section{Social connectedness and loneliness}

Participation in a group setting is well known to decrease Ioneliness if the connection is facilitated in the correct way, and this can be seen in the results for the SOTW program. A recent review found that the most successful interventions for loneliness address maladaptive social cognitions as well as provide social supports. ${ }^{33}$ Inclusion in a group with a sense of community and identification with a football club may create these altered cognitions and increase resilience in SOTW participants; however, the ways in which it might do this are as yet unclear.

\section{Help-seeking behaviour}

The findings reported here show that a large number of men indicated they did not have sufficient mental healthcare at the beginning of the program. The large number of men who did not follow through on their initial request for psychological help after being contacted suggests that barriers to seeking help, such as time, geographical distance or inability to understand how psychological services could help, may still remain. However, a large proportion of participants received peer or professional help within or external to the program as a result of SOTW participation. This is a promising finding. Further research is needed to explore this finding in a longitudinal sample, to determine any effect on those who are in the program for the full 3 years.

\section{Limitations}

This study contains data gathered at the start and end of the 10-week program only, and does not include longitudinal follow-up. Change achieved during many physical and mental health interventions is often not sustained. ${ }^{34}$ It would be beneficial to conduct a study with long-term follow-up. In addition, the study did not include a control group of demographic-matched participants in the general community, or in other less-intensive health promotion programs. This pre-post analysis did not distinguish whether participants were in year one, two or three of the program. It would be beneficial to understand whether change is more or less substantial in later years of participation.

As indicated, some of the improvements across measures did not show statistical significance. However, it is important to highlight that, as a program which is intended to have incremental impact across 3 years, the changes across each year of the program may be cumulative. However, this has not been fully established. Again, some form of longitudinal research is required.

The SOTW program is also a voluntary participation group and there was no randomisation of the group. A meta-analysis of interventions aimed at decreasing loneliness in adults revealed that single group pre-post and nonrandomised comparison studies showed larger effects than randomised studies. ${ }^{33}$ It is possible that the program only provides benefits to those who are willing to participate. Given the large numbers of participants, this may not necessarily be a problem for the SOTW program and its ability to have an impact in the west of Victoria. However, it does reduce the ability to make suggestions about the generalisability of the program to other populations.

The authors took all due diligence to keep the collection and analysis of data within the research team (Victoria University investigators or placement students). However, it is acknowledged that data was captured at the SOTW sites and during program weeks which may have influenced participants' perception of the study's independence and potentially influenced responses. A separate confidential survey is recommended to see whether results are replicated in a completely private setting.

\section{Conclusion}

This small-scale study shows promising results for a large gender-sensitised health promotion program for men. It shows that the program has had a positive impact on men's psychological health. There are still many ways in which the change mechanisms of the program are yet to be elucidated; however, the program shows strong potential for further research and possible generalisation to other populations.

\section{Acknowledgements}

WBCF conceived the Sons of the West program and coordinated a joint WBCF effort with eight Local Government Area Councils. The author would like to thank the WBCF staff, in particular Catherine Dell'Aquila, for their assistance with access to participants, logistical support and background on the program.

\section{Peer review and provenance}

Externally peer reviewed, not commissioned.

\section{Competing interests}

None declared.

\section{Author contributions}

CLD conceived the study and led all aspects, including analysis and drafting the paper. Data collection was completed in collaboration with placement students from Victoria University. 


\section{References}

1. Australian Bureau of Statistics. Gender indicators, Australia, Sep 2017. Canberra: ABS; 2017 [cited 2020 Jan 6]. Available from: www.abs.gov.au/ausstats/ abs@.nsf/Lookup/by\%20Subject/4125.0 Sep\%20 2017 Main\%20Features Key\%20Series\%20and\%20 Indicators\%20 3

2. Australian Institute of Health and Welfare. Australia's welfare 2011. Canberra: AlHW; 2011 [cited 2019 Dec 17] Available from: www.aihw.gov.au/getmedia/658dc9a16e55-4161-b26f-bcd45c014ff6/12927.pdf. aspx?inline $=$ true

3. Hawkes S, Buse K. Gender and global health: evidence, policy, and inconvenient truths. Lancet. 2013;381(9879):1783-7.

4. Bayram C, Valenti L, Britt H. General practice encounters with men. Aust Fam Physician. 2016;45(4):171-4.

5. Boman EKO, Walker GA. Predictors of men's health care utilization. Psychol Men Masc. 2010;11:9.

6. Australian Bureau of Statistics. Life tables, states, territories and Australia, 2016-2018. Canberra: ABS; 2019. [cited 2020 Jan 6]. Available from: www.abs.gov. au/ausstats/abs@.nst/mf/3302.0.55.001

7. Breslin G, McCay N. Perceived control over physical and mental well-being: the effects of gender, age and social class. J Health Psychol. 2013;18(1):38-45.

8. Rice SM, Aucote HM, Parker A, Alvarez-Jimenez M, Filia KM, Amminger GP. Men's perceived barriers to help seeking for depression: longitudinal findings relative to symptom onset and duration. J Health Psychol. 2015;22(5):529-36.

9. Slaunwhite A. The role of gender and income in predicting barriers to mental health care in Canada. Community Ment Health J. 2015;51(5):621-7.

10 Pirkis J, Macdonald J, English DR. Introducing Ten to Men, the Australian longitudinal study on male health. BMC Public Health. 2016;16(Suppl 3):1044.

11. Clement S, Schauman O, Graham T, Maggioni F, EvansLacko S, Bezborodovs N, et al. What is the impact of mental health-related stigma on help-seeking? A systematic review of quantitative and qualitative studies. Psychol Med. 2015;45(1):11-27.

12. Lindsey MA, Korr WS, Broitman M, Bone L, Green A, Leaf PJ. Help seeking behaviors and depression among African American adolescent boys. Soc Work. 2006;51(1):49-58.

13. Mojtabai R, Evans-Lacko S, Schomerus G, Thornicroft G. Attitudes toward mental health help seeking as predictors of future help-seeking behavior and use of mental health treatments. Psychiatr Serv. 2016;67(6):650-7.

14. Möller-Leimkühler A. Barriers to help-seeking by men: a review of sociocultural and clinical literature with particular reference to depression. J Affect Disord. 2002;71(1-3):19.
15. Browne GB, Arpin K, Corey P, Fitch M, Gafni A. Individual correlates of health service utilization and the cost of poor adjustment to chronic illness. Med Care. 1990;28(43-58).

16. Webb TL, Sheeran P. Does changing behavioral intentions engender behavior change? A metaanalysis of the experimental evidence. Psychol Bulletin. 2006;132(2):249-68.

17. Holt-Lunstad J, Smith TB, Layton JB. Social relationships and mortality risk: a meta-analytic review. PLoS Med. 2010;7(7):e1000316.

18. Doyal L. Sex, gender, and health: the need for a new approach. BMJ. 2001;323(7320):1061-3.

19. Smith JA. Beyond masculine stereotypes: moving men's health promotion forward in Australia. Health Prom $\mathrm{J}$ Austr. 2007;18(1):20-5.

20. Australian Bureau of Statistics. Melbourne - West 2016 Census QuickStats. Canberra: ABS; 2016 [cited 2019 Dec 17]. Available from: quickstats.censusdata.abs. gov.au/census_services/getproduct/census/2016/ quickstat/213?opendocument

21. Australian Bureau of Statistics. Census of population and housing: Socio-Economic Indexes for Areas (SEIFA), Australia 2016. Canberra: ABS; 2018 [cited 2020 Jan 6]. Available from: www.abs.gov.au/ausstats/abs@.nsf/ $\mathrm{mf} / 2033.0 .55 .001$

22. Banting L. Sons of the West health and participant outcomes 2015. Melbourne: Victoria University; 2015. Copy available from author.

23. Naccarella L. Evaluating the Western Bulldogs Football Club Sons of the West program. Melbourne: University of Melbourne; 2016. Copy available from author.

24. Fraser T, Kostrz K. Health activity programs that target inactive men in the community: a review. Melbourne: Victoria University; 2018. Copy available from author.

25. Kessler RC, Barker PR, Colpe LJ, Epstein JF, Gfroerer JC, Hiripi E, et al. Screening for serious mental illness in the general population. Arch Gen Psychiatry. 2003;60(2):1849.

26. Australian Bureau of Statistics. Information paper: use of the Kessler Psychological Distress Scale in ABS health surveys, Australia, 2001. Canberra: ABS; 2003 [cited 2019 Dec 17]. Available from: www.abs.gov.au/ausstats/ abs@.nst/ProductsbyReleaseDate/4D5BD324FE8B415FC A2579D500161D57

27. Smith B, Dalen J, Wiggins K, Tooley E, Christopher P, Bernard J. The brief resilience scale: assessing the ability to bounce back. Int J Behav Med. 2008;15(3):194-200.

28. Lim MH, Rodebaugh TL, Zyphur MJ, Gleeson JF. Loneliness over time: the crucial role of social anxiety. J Abnorm Psychol. 2016;125(5):620-30.

29. Knight RG, Chisholm BJ, Marsh NV, Godfrey HD. Some normative, reliability, and factor analytic data for the Revised UCLA Loneliness Scale. J Clinic Psychol. 1988;44(2):203-6. 
30. Australian Bureau of Statistics. Regional population by age and sex, Australia, 2017. Canberra: ABS; 2018. [cited 2020 Jan 6]. Available from: www.abs.gov.au/AUSSTATS/ abs@.nsf/DetailsPage/3235.02017

31. Australian Bureau of Statistics. Microdata: national health survey: 2014-2015. Canberra: ABS; 2016 [cited 2020 Jan 6]. Available from: www.abs.gov.au/ausstats/abs@.nsf/Loo kup/4324.0.55.001main+features12014-15

32. Hayes R, Williamson M. Evidence-based, best-practice guidelines for Victorian men's sheds. Bundoora, Australia: School of Public Health, La Trobe University, 2006. Copy available from author.
33. Masi CM, Chen H-Y, Hawkley LC, Cacioppo JT. A metaanalysis of interventions to reduce loneliness. Pers Soc Psychol Rev. 2011;15(3):219-66.

34. Quigley L, Marlatt A. Relapse prevention: maintenance of change after initial treatment. In: McCrady BS, Epstein EE, editors. Addictions: a comprehensive guidebook. New York: Oxford University Press; 1999.

\section{Copyright: (C) $(1)(0)$}

(C) 2020 Deans. This article is licensed under the Creative Commons Attribution-NonCommercial-ShareAlike 4.0 International Licence, which allows others to redistribute, adapt and share this work non-commercially provided they attribute the work and any adapted version of it is distributed under the same Creative Commons licence terms. See: www.creativecommons.org/licenses/by-nc-sa/4.0/ 